\title{
INTER-ORGANIZATIONAL COOPERATIVE INNOVATION OF PROJECT-BASED SUPPLY CHAINS UNDER CONSIDERATION OF MONITORING SIGNALS
}

\author{
Wu, G.-D.* \& Tang, D.-Z.** \\ * Jiangxi University of Finance \& Economics, Nanchang, 330013, Jiangxi, China \\ ${ }^{* *}$ Tongji University, Shanghai, 200092, China \\ E-Mail: tdzhong@126.com $\left({ }^{* *}\right.$ Corresponding author $)$
}

\begin{abstract}
Assuming project-based organizations cooperate equally, this paper used principal-agent theory and game theory, to empower the general contractor to give reward and punishment to the professional sub-contractor based on a monitoring signal and constructed a model of inter-organizational cooperative innovation of project-based supply based on a monitoring signal. Based on the model, by data simulation and example analysis, as well as comparison with a traditional model, we came to the conclusion that the general contractor, through a monitoring signal, is able to collect more information on the professional sub-contractor's knowledge sharing and concealing level. Thus by adjusting the reward and punishment level, it can not only lower the professional sub-contractor's knowledge concealing level, but can also raise the knowledge sharing level, all of which will reduce the professional sub-contractor's opportunism and the blindness the general contractor may be alleviated in the design motivation mechanism.

(Received, processed and accepted by the Chinese Representative Office.)
\end{abstract}

Key Words: Project-Based Supply Chain, Cooperative Innovation, Monitoring Signal

\section{INTRODUCTION}

Construction is an information and knowledge driven industry. Construction firms all over the world are increasingly being challenged by the pressures of high-cost, shortened project cycles and increasing competition. Within a business environment, where fast and reliable access to knowledge is a key success factor, the efficient handling of organizational knowledge is crucial [1]. Cooperation is necessary for achieving knowledge quickly and reliably since cooperation among project-based organizations lays the foundation of knowledge innovation. In the inter-organizational cooperative innovation of project-based supply chain, the relationship among project-based organizations remains unchanged once it is established [2]. Because of the difficulty in exactly measuring the output benefits, common errors frequently occur in inter-organizational cooperative innovation of project-based supply chains. Further, the large number of project-based organizations involved in cooperative innovation makes it hard to realize actual cooperative innovation and results in project-based organizations' counteracting each other [3-4]. The complexity of the often uncertain and temporal nature of construction projects makes it more likely for participants to compromise their moral integrity and take unscrupulous risks. Compared with the supply chain of the general manufacturing industry, project-based supply chains are characterized by high fragmentation, low productivity, cost and time overruns, and conflicts and disputes [5]. By considering one specific objective of the project and the effect of project-based organizations' behavioural preference pertaining to that objective, the ensuing behaviour of project-based organizations can be predicted and judged effectively and measures can be adopted accordingly [6].

The supply chain management mode has improved the traditional project management vertical organization structure by responding quickly to consumer demand and market change 
and reshaped the adversarial relationship among participants into a community interested in mutual benefit [7]. Therefore, some scholars have studied inter-organizational cooperative innovation of project-based supply chains. He et al. [8] argued that the ability of acquiring knowledge has an impact on knowledge innovation and influences future supply chain performance. Ramanathan [9] simulated the innovation performance in supply chain coordination based on real data of organization size, organization number and investment level. Ramanathan and Gunasekaran [10] considered coordination and cooperation among organizations and built a supply chain coordination model to undergo empirical study. They found that effective implementation of a plan of cooperation and highly active coordination of policy making can improve the relationship among node enterprises and increase the possibility of cooperation in the future. He et al. [11] took the knowledge innovation perspective and used a complete information dynamic game to conduct the research possible game between the main design organization and professional design organization. They obtained the revenue and total revenue of all parties with different bidding strategies, as well as the characteristics of each mode and the strategies being used.

A proper motivation mechanism is important for successful cooperation among node enterprises' cooperative innovation. However, the high cost of inter-organizational cooperative innovation of project-based supply chains, behavioural choices of node enterprises play a critical role in knowledge innovation performance [12]. How to design a benefit sharing agreement endorsed by all participants and how to make policy on practical cooperative innovation behaviours are the key factors for the success of inter-organizational cooperative innovation of project-based supply chains. Therefore, this paper, based on the principal agent theory and game theory, introduced a monitoring signal and studied the cooperative innovation between the general contractor and the professional sub-contractor. The author explored how project-based organizations determine their effort levels and how to design fair motivation mechanism for cooperative innovation, expecting to obtain practical and well-directed strategies.

\section{PROBLEM DESCRIPTION AND BASIC ASSUMPTIONS}

The inter-organizational cooperative innovation of project-based supply chains is the interplay among project-based organizations. Actually, it is the process of knowledge flowing and delivering among project-based organizations, which realizes the interplay among project-based organizations and forms the foundation for cooperative innovation of project-based supply chains and project value-adding [13]. A project-based supply chain consists of the owner, design organization, general contractor, professional sub-contractor and so forth, which is a typical inter-organizational structure centering the project. Project value-adding is the origin of profits of the whole supply chain and the benefits of all project-based organizations. Here, we considered a two-order project-based supply chain made only by the general contractor and the professional sub-contractor and made the following assumptions.

The owner and the general contractor are rational organizations that pursue maximized interests. Both of them have complete information on knowledge need in carrying out the project.

In the project-based supply chain, the general contractor is the dominant enterprise and is risk-neutral. It has absolute control and leadership and is in charge of designing a motivation mechanism for the whole supply chain. The general contractor and the professional sub-contractor sign a principal-agent contract in order to deliver the project successfully. Assuming project-based organizations are rational economic bodies, they pursue maximized interests and are risk-averse. According to the relationship between risk attitude and utility 
function, the utility function for a risk-averse project-based organization can be expressed as $U(\omega)=-e^{-\rho \omega}$, where $\omega$ is the benefit function of the project-based organization, $\rho$ is absolute risk aversion degree calculated with the Arrow-Pratt method. The risk cost for the project-based organization is $1 / 2 \rho \operatorname{Var}(\omega)$.

In inter-organizational cooperative innovation of project-based supply chains, the professional sub-contractor has two behaviour strategies $e=\left(e_{1}, e_{2}\right)$ for choices. $e_{1}$ is knowledge sharing behaviour and $e_{2}$ is knowledge concealing behaviour. That means the professional sub-contractor can chose to share knowledge or conceal knowledge as the project proceeds.

The professional sub-contractor's knowledge sharing behaviour can transform knowledge into output with the output function of $\pi_{1}=\kappa_{1} e_{1}+\varepsilon_{1}$ [14], where $\kappa_{1}$ is a constant that indicates the professional sub-contractor's capability to get benefits through knowledge sharing and $\varepsilon_{1}$ represents an uncertain impact caused by outside random factors and follows $\mathrm{N} \sim\left(0, \sigma_{1}{ }^{2}\right)$.

The professional sub-contractor is always faced with risks whichever strategy it chooses. On one hand, sharing knowledge may lead to a loss of its core competitiveness loss. On the other hand, concealing knowledge may cause other members' exclusion and negative comments. Assuming the cost of sharing knowledge and concealing knowledge is $c_{1}=1 / 2 \eta_{1} e_{1}^{2}$ and $c_{2}=1 / 2 \eta_{2} e_{2}^{2}[15]$, the total cost of the two behaviours is:

$$
C\left(e_{1}, e_{2}\right)=1 / 2 \eta_{1} e_{1}^{2}+1 / 2 \eta_{2} e_{2}^{2}
$$

where $\eta_{1}$ and $\eta_{2}$ are positive constants, indicating the cost coefficients for knowledge sharing and concealing, respectively.

Since Holmstrom et al. has proved that a linear contract can reach the optimum and it is widely used in motivation contract study, here we assumed that the general contractor design motivation contract $\omega$ according to actual project revenue $\pi=\pi_{1}-\pi_{2}$, and we have $\omega=\alpha+\beta \pi$ where $\alpha$ is the fixed compensation paid by the general contractor to the professional sub-contractor and $\beta \in(0,1)$ is the professional sub-contractor's revenue sharing coefficient, which is a constant.

\section{MODEL CONSTRUCTION AND SOLUTION}

\subsection{Basic motivation mechanism model}

Based on assumptions, the general contractor's expected utility function is:

$$
E(V)=-\alpha+(1-\beta)\left(\kappa_{1} e_{1}-\kappa_{2} e_{2}\right)
$$

Under risk aversion scenario, the certain equivalent revenue of the professional sub-contractor is the difference between its expected revenue and risk cost. Since the professional sub-contractor's maximized expected utility function is equal to its maximized certain revenue, the maximized utility can be expressed by the certain equivalent revenue as below:

$$
E(\mathrm{U})=\alpha+\beta \kappa_{1} e_{1}+(1-\beta) \kappa_{2} e_{2}-\frac{1}{2}\left(\eta_{1} e_{1}^{2}+\eta_{2} e_{2}^{2}\right)-\frac{1}{2} \rho\left[\beta^{2} \sigma_{1}^{2}+(1-\beta)^{2} \sigma_{2}^{2}\right]
$$

Here, the general contractor's organization problem is changed to the choice of $e=\left(e_{1}, e_{2}\right)$ to maximize its revenue. The motivation mechanism designed by the general contractor can be described through the principal-agent model as follows: 


$$
\begin{aligned}
& \max _{\beta, e_{1}, e_{2}} E(V)=\max \left[-\alpha+(1-\beta)\left(\kappa_{1} e_{1}-\kappa_{2} e_{2}\right)\right] \\
& \text { s.t. }(I R): \alpha+\beta \kappa_{1} e_{1}+(1-\beta) \kappa_{2} e_{2}-\frac{1}{2}\left(\eta_{1} e_{1}^{2}+\eta_{2} e_{2}^{2}\right)-\frac{1}{2} \rho \beta^{2} \sigma_{1}^{2}-\frac{1}{2} \rho(1-\beta)^{2} \sigma_{2}^{2} \geq \bar{U} \\
& \qquad(I C): \max _{e_{1}, e_{2}} \alpha+\beta \kappa_{1} e_{1}+(1-\beta) \kappa_{2} e_{2}-\frac{1}{2}\left(\eta_{1} e_{1}^{2}+\eta_{2} e_{2}^{2}\right)-\frac{1}{2} \rho \beta^{2} \sigma_{1}^{2}-\frac{1}{2} \rho(1-\beta)^{2} \sigma_{2}^{2}
\end{aligned}
$$

With incomplete information, the motivation mechanism in inter-organizational cooperative innovation of project-based supply chains is actually to solve the above optimization problem. Let the first-order derivative of the motivation-binding compatible condition $(I C)$ be 0 , and we will get the optimum effort levels of the professional sub-contractor in knowledge sharing and concealing respectively:

$$
e_{1}=\frac{\beta \kappa_{1}}{\eta_{1}} \quad e_{2}=\frac{(1-\beta) \kappa_{2}}{\eta_{2}}
$$

Under optimum conditions, the left equals the right of the participation-binding condition $(I R)$, which means the general contractor has no need to pay the professional sub-contractor extra compensation. Thus, we got the fixed compensation as below:

$$
\alpha=\bar{U}-\beta \kappa_{1} e_{1}-(1-\beta) \kappa_{2} e_{2}+\frac{1}{2}\left(\eta_{1} e_{1}^{2}+\eta_{2} e_{2}^{2}\right)+\frac{1}{2} \rho\left[\beta^{2} \sigma_{1}^{2}+(1-\beta)^{2} \sigma_{2}^{2}\right]
$$

If we substitute eqs. (5) and (6) with the objective function, solve the derivative of the optimum motivation coefficient $\beta$, and let it be 0 , we will get:

$$
\beta^{*}=\frac{1}{1+\frac{\rho \kappa_{1} \kappa_{2} \sigma_{1}^{2}}{\eta_{2} \kappa_{1}^{2}+\eta_{1} \kappa_{2}^{2}+\rho \kappa_{1} \kappa_{2} \sigma_{2}^{2}}}
$$

Because $\eta_{1}, \eta_{2}, \kappa_{1}$ and $\kappa_{2}$ are all positive constants, we have $0<\beta^{*}<1$. Under revenue sharing mechanism, the professional sub-contractor's optimum strategy combination is shown below:

$$
e^{*}=\left(e_{1}, e_{2}\right)=\left(\frac{\beta^{*} \kappa_{1}}{\eta_{1}}, \frac{\left(1-\beta^{*}\right) \kappa_{2}}{\eta_{2}}\right)
$$

\subsection{Motivation mechanism model considering a monitoring signal}

The basic model above considers a motivation mechanism in cooperative innovation only [16]. Here, we add a supervision mechanism. With the same assumptions for the basic model, we introduced two monitoring signals: $y_{1}$ and $y_{2} \cdot y_{1}$ is the signal observed based on knowledge sharing behaviour and $y_{2}$ is the signal observed based on knowledge concealing behaviour where $y_{1}=e_{1}+\theta_{1}$ and $y_{2}=e_{2}+\theta_{2} . \theta_{1}$ and $\theta_{2}$ are random independent variables following $\mathrm{N} \sim\left(0, \delta_{1}\right)$ and $\mathrm{N} \sim\left(0, \delta_{2}\right)$ respectively and reflect the accuracy of the monitoring signals. Accordingly, the linear motivation contract is modified as $\omega=\alpha+\beta \pi+\gamma_{1} y_{1}-\gamma_{2} y_{2}$, where $\gamma_{1}$ and $\gamma_{2}$ are compensation payment sharing coefficients determined by monitoring signals. $\gamma_{1} y_{1}$ is the additional reward determined by knowledge sharing signal and $\gamma_{1}$ is the reward coefficient. $\gamma_{2} y_{2}$ is an additional penalty determined by knowledge concealing signal and $\gamma_{2}$ is the penalty coefficient. After introducing monitoring signals, the professional sub-contractor's revenue is determined not only by the output of knowledge sharing, but also by the monitoring signals observed by the general contractor, which will lead to a more fair motivation contract design. Similarly, the general contractor's expected utility function is shown below: 


$$
E(V)=-\alpha+(1-\beta)\left(\kappa_{1} e_{1}-\kappa_{2} e_{2}\right)-\gamma_{1} y_{1}+\gamma_{2} y_{2}
$$

The professional sub-contractor's expected utility function is:

$$
E(\mathrm{U})=\alpha+\beta \kappa_{1} e_{1}+(1-\beta) \kappa_{2} e_{2}+\gamma_{1} y_{1}-\gamma_{2} y_{2}-\frac{1}{2}\left(\eta_{1} e_{1}^{2}+\eta_{2} e_{2}^{2}\right)-\frac{1}{2} \rho\left[\beta^{2} \sigma_{1}^{2}+(1-\beta)^{2} \sigma_{2}^{2}\right]
$$

Therefore, we can arrive at the improved principal-agent model considering monitoring signals.

$$
\begin{aligned}
& \max _{\beta, e_{1}, e_{2}} E(V)=\max \left[-\alpha+(1-\beta)\left(\kappa_{1} e_{1}-\kappa_{2} e_{2}\right)-\gamma_{1} y_{1}+\gamma_{2} y_{2}\right] \\
& \text { s.t. }(I R): \alpha+\beta \kappa_{1} e_{1}+(1-\beta) \kappa_{2} e_{2}+\gamma_{1} y_{1}-\gamma_{2} y_{2}-\frac{1}{2}\left(\eta_{1} e_{1}^{2}+\eta_{2} e_{2}^{2}\right)-\frac{1}{2} \rho \beta^{2} \sigma_{1}^{2}-\frac{1}{2} \rho(1-\beta)^{2} \sigma_{2}^{2} \geq \bar{U} \\
& \quad(I C): \max _{e_{1}, e_{2}} \alpha+\beta \kappa_{1} e_{1}+(1-\beta) \kappa_{2} e_{2}+\gamma_{1} y_{1}-\gamma_{2} y_{2}-\frac{1}{2}\left(\eta_{1} e_{1}^{2}+\eta_{2} e_{2}^{2}\right)-\frac{1}{2} \rho \beta^{2} \sigma_{1}^{2}-\frac{1}{2} \rho(1-\beta)^{2} \sigma_{2}^{2}
\end{aligned}
$$

Let the first-order derivative of the motivation-binding compatible condition $(I C)$ be 0 , and we will get the optimum effort levels of the professional sub-contractor in knowledge sharing and concealing respectively:

$$
e_{1}=\frac{\beta \kappa_{1}+\gamma_{1}}{\eta_{1}} \quad e_{2}=\frac{(1-\beta) \kappa_{2}-\gamma_{2}}{\eta_{2}}
$$

Under optimum conditions, the left equals the right of the participation-binding condition $(I R)$, which means the general contractor has no need to pay the professional sub-contractor extra compensation. Thus, the fixed compensation is as below:

$$
\alpha=\bar{U}-\beta \kappa_{1} e_{1}-(1-\beta) \kappa_{2} e_{2}-\gamma_{1} y_{1}+\gamma_{2} y_{2}+\frac{1}{2}\left(\eta_{1} e_{1}^{2}+\eta_{2} e_{2}^{2}\right)+\frac{1}{2} \rho\left[\beta^{2} \sigma_{1}^{2}+(1-\beta)^{2} \sigma_{2}^{2}\right]
$$

Substitute eqs. (12) and (13) with the objective function, solve the derivative of the optimum motivation coefficient $\beta$, and let it be 0 , we will get:

$$
\beta^{* *}=\frac{1}{1+\frac{\rho \kappa_{1} \kappa_{2} \sigma_{1}^{2}}{\eta_{2} \kappa_{1}^{2}+\eta_{1} \kappa_{2}^{2}+\rho \kappa_{1} \kappa_{2} \sigma_{2}^{2}}}-\frac{\eta_{1} \kappa_{2} \gamma_{2}+\eta_{2} \kappa_{1} \gamma_{1}}{\eta_{1} \kappa_{2}^{2}+\eta_{2} \kappa_{1}^{2}+\eta_{1} \eta_{2} \rho\left(\sigma_{1}^{2}+\sigma_{2}^{2}\right)}
$$

Because $\eta_{1}, \eta_{2}, \kappa_{1}$ and $\kappa_{2}$ are all positive constants, we have $0<\beta^{* *}<1$. Under the revenue sharing mechanism, the professional sub-contractor's optimum strategy combination is shown below:

$$
e^{* *}=\left(e_{1}, e_{2}\right)=\left(\frac{\beta^{* *} \kappa_{1}+\gamma_{1}}{\eta_{1}}, \frac{\left(1-\beta^{* *}\right) \kappa_{2}-\gamma_{2}}{\eta_{2}}\right)
$$

\section{MODEL ANALYSIS AND CONCLUSIONS}

Conclusion 1. According to eqs. (8) and (15), the professional sub-contractor's choice of optimum behaviour based on the maximization of its interest is independent of the fixed compensation $\alpha$ in the payment function, no matter if it is under revenue sharing motivation mechanism only or also considering monitoring signals. That means fixed compensation exerts no motivation to the professional sub-contractor's choice. For both $e^{*}$ and $e^{* *}$, we have $\frac{\partial e_{1}}{\partial \beta}>0$ and $\frac{\partial e_{2}}{\partial \beta}<0$, which means the professional sub-contractor's knowledge sharing behaviour is positively related to the optimum revenue sharing coefficient while its knowledge concealing behaviour is negatively related to the optimum revenue sharing coefficient. That means revenue sharing has the effect of promoting knowledge sharing and 
curbing knowledge concealment. Therefore, in inter-organizational cooperative innovation of project-based supply chains, the general contractor can raise revenue sharing coefficient so as to motivate the professional sub-contractor to share knowledge and frustrate their knowledge concealing behaviour.

Conclusion 2. According to eq. (15), we have $\frac{\partial e_{1}}{\partial \beta^{* *}}>0$ and $\frac{\partial e_{1}}{\partial \gamma_{1}}>0$, which indicates both the motivation mechanism and the monitoring mechanism help to promote the professional sub-contractor's knowledge sharing behaviour. Furthermore, we have $\frac{\partial e_{2}}{\partial \beta^{* *}}<0$ and $\frac{\partial e_{2}}{\partial \gamma_{2}}<0$, which means both the motivation mechanism and the monitoring mechanism help to constrain the professional sub-contractor's knowledge sharing behaviour. Comparing $\beta^{*}$ and $\beta^{* *}$, we have $\beta^{*}>\beta^{* *}$; i.e., the optimum sharing coefficient under a monitoring mechanism is smaller than that under a motivation mechanism. This is because under a monitoring mechanism, the general contractor is able to collect and master more information, thus reducing the information asymmetry and the professional sub-contractor's opportunistic behaviour and increasing its cost of concealing knowledge. Therefore, the introduction of a monitoring signal helps the general contractor to design a contract more fairly.

Conclusion 3 After introducing a monitoring signal, the professional sub-contractor's knowledge sharing effort level becomes higher than that without a monitoring signal, and its knowledge concealing behaviour is constrained to some extent. When $\beta^{*} \rightarrow 0, e^{*}=\left(e_{1}, e_{2}\right) \rightarrow$ $\left(0, \kappa_{2} / \eta_{2}\right)$, indicating when no monitoring mechanism nor the general contractor's motivation exists, the professional sub-contractor's knowledge sharing effort level is 0 but knowledge concealing behaviour still exists. This means that the professional sub-contractor, in order to maximize its revenue will not share knowledge but practice concealment. When $\beta^{* *} \rightarrow 0$, $e^{* *}=\left(e_{1}, e_{2}\right) \rightarrow\left(\frac{\gamma_{1}}{\eta_{1}}, \frac{\kappa_{2}-\gamma_{2}}{\eta_{2}}\right)$, which means that even without motivation, the effect of the possible penalty imposed by the monitoring mechanism will lead the professional sub-contractor to share knowledge to some extent to avoid the penalty and maximize its revenue. At the same time, $\frac{\kappa_{2}-\gamma_{2}}{\eta_{2}}<\frac{\kappa_{2}}{\eta_{2}}$ means that the professional sub-contractor's knowledge concealing behaviour will be frustrated to some extent.

Conclusion 4 According to eq. (14), we have:

$$
\begin{aligned}
& \frac{\partial \beta^{* *}}{\partial \gamma_{1}}=-\frac{\eta_{2} \kappa_{1}}{\eta_{1} \kappa_{2}^{2}+\eta_{2} \kappa_{1}^{2}+\eta_{1} \eta_{2} \rho\left(\sigma_{1}^{2}+\sigma_{2}^{2}\right)}<0 \\
& \frac{\partial \beta^{* *}}{\partial \gamma_{2}}=-\frac{\eta_{1} \kappa_{2}}{\eta_{1} \kappa_{2}^{2}+\eta_{2} \kappa_{1}^{2}+\eta_{1} \eta_{2} \rho\left(\sigma_{1}^{2}+\sigma_{2}^{2}\right)}<0
\end{aligned}
$$

This means that under a monitoring mechanism, the revenue sharing coefficient based on knowledge sharing output and that based on a monitoring signal are negatively related; i.e. when the output produced by the professional sub-contractor's knowledge sharing shows high uncertainty due to outside random factors, the general contractor can make use of the monitoring signal to adjust the optimum revenue sharing coefficient, thus adjusting the actual revenue obtained by the professional sub-contractor and maintaining the effectiveness of the motivation contract. 


\section{DATA SIMULATION AND MODEL EXAMPLE}

Since the fixed compensation $\alpha$ offered by the general contractor does not influence the motivation effect or the professional sub-contractor's behaviour choice, we assume $\alpha=0$. According to model assumptions, values of constants are set as:

$$
\rho=0.6, \eta_{1}=\eta_{2}=1, \kappa_{1}=4, \kappa_{2}=2, \sigma_{1}^{2}=0.005, \sigma_{2}^{2}=0.01 \text {. }
$$

\subsection{Relationship between the professional sub-contractor's choice of behaviour and revenue sharing coefficient}

Let $\gamma_{1}=0.5$ and $\gamma_{2}=0.8$, and substitute related constants to eqs. (8) and (15), and we have:

$$
e_{1}=\left\{\begin{array}{l}
4 \beta \\
4 \beta+0.5
\end{array} e_{2}=\left\{\begin{array}{l}
2(1-\beta) \\
2(1-\beta)-0.8
\end{array}\right.\right.
$$

Simulating data by Origin 9.0, we arrive at the figures below.
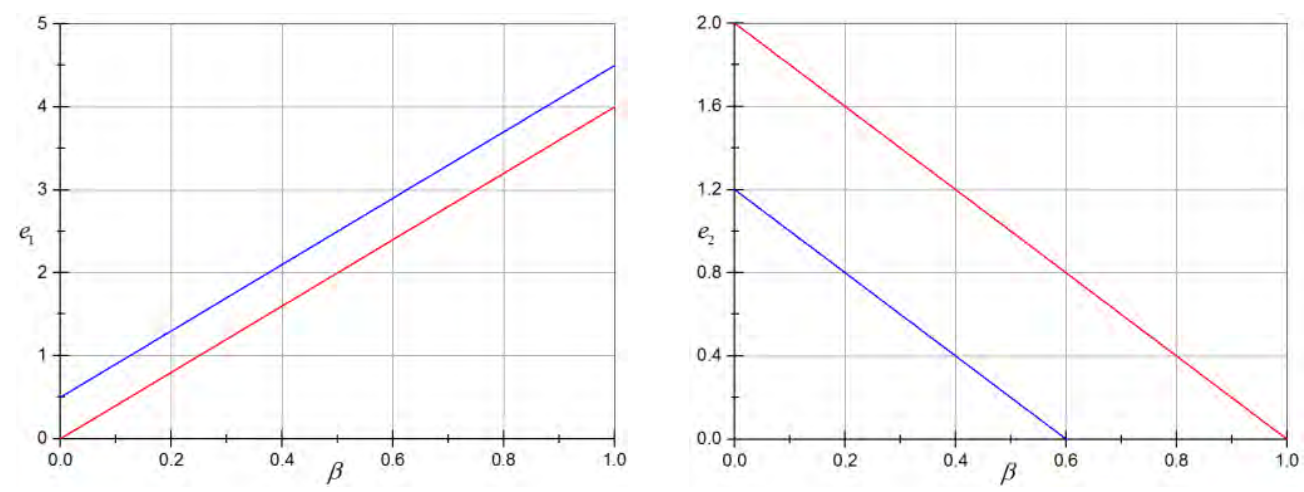

Figure 1: Relationship between the professional sub-contractor's choice of behaviour and revenue sharing coefficient.

According to the above figures, for the given revenue sharing coefficient $\beta$, after introducing a monitoring signal, the professional sub-contractor's knowledge sharing effort level is higher than that under the traditional motivation mode, while its knowledge concealing effort level is lower than that under the traditional motivation mode. This indicates, after introducing monitoring signals, the professional sub-contractor's knowledge sharing behaviour is promoted and knowledge concealing behaviour is constrained to some extent, coinciding with conclusions 1 and 3.

\subsection{Relationship between the professional sub-contractor's choice of behaviour and a monitoring signal}

Substituting related parameters with eq. (15), we have:

$$
\left\{\begin{array} { l } 
{ e _ { 1 } = 4 \beta + \gamma _ { 1 } } \\
{ e _ { 2 } = 2 - 2 \beta - \gamma _ { 2 } }
\end{array} \quad \left\{\begin{array}{l}
e_{1}=3.6+0.2 \gamma_{1}-0.4 \gamma_{2} \\
e_{2}=0.2-0.6 \gamma_{1}+0.2 \gamma_{2}
\end{array}\right.\right.
$$

Using Origin 9.0 to simulate data, we arrived at figures as follows. Fig. $2 \mathrm{a}$ is the result under consideration of the effect of revenue sharing coefficient and a monitoring signal on the professional sub-contractor's choice of behaviour, where the $\mathrm{X}$ axis is revenue sharing coefficient, the $\mathrm{Y}$ axis is monitoring signal and the $\mathrm{Z}$ axis is behavioural choice level. Fig. $2 \mathrm{~b}$ is the effect of the monitoring signal on the professional sub-contractor's behavioural choice when $\beta=0.3$. Fig. $2 \mathrm{c}$ is the result of the effect of a reward coefficient and a penalty coefficient on the professional sub-contractor's behavioural choice, where the $\mathrm{X}$ axis is the 
reward coefficient based on monitoring signal, the $\mathrm{Y}$ axis is the penalty coefficient based on the monitoring signal and the $\mathrm{Z}$ axis is the revenue sharing coefficient.
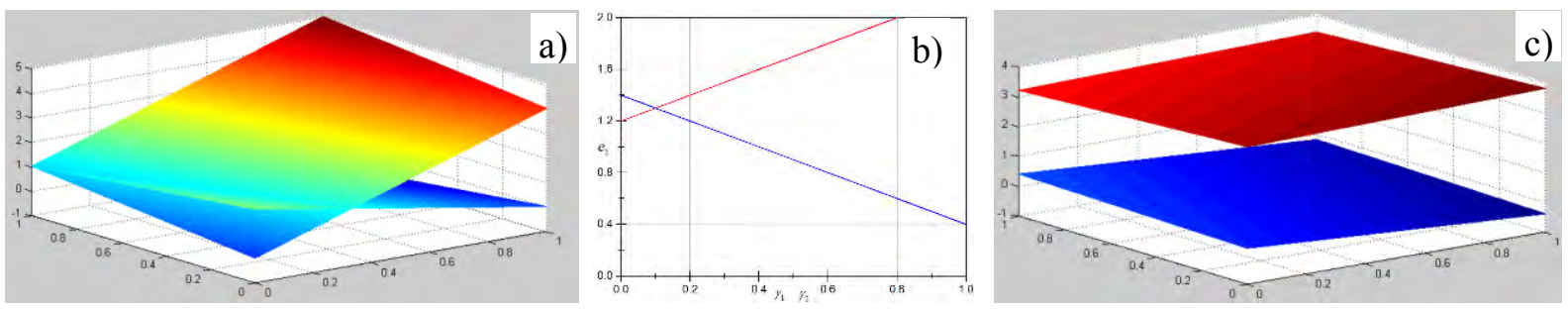

Figure 2: Relationship between the professional sub-contractor's behavioural choice and the monitoring signal.

From Fig. $2 \mathrm{a}$ and Fig. $2 \mathrm{~b}$, the given revenue sharing coefficient $\beta$ with a monitoring signal, the professional sub-contractor's knowledge sharing level is the increasing function, while its knowledge concealing behaviour is the decreasing function of the monitoring signal, indicating that the monitoring signal serves to promote knowledge sharing and frustrate knowledge concealing as conclusions 2 and 3 show. As Fig. $2 \mathrm{a}$ and Fig. $2 \mathrm{c}$ show, the professional sub-contractor's knowledge sharing behaviour is influenced not only by the reward coefficient based on the monitoring signal, but also by the penalty coefficient. The larger reward coefficient and smaller punishment coefficient lead to higher a knowledge sharing level. On the contrary, the smaller reward coefficient and larger penalty coefficient lead to a higher knowledge concealing level. Therefore, with a monitoring signal, the general contractor should not only consider the exact reward and penalty for the professional sub-contractor, but also balance them when designing a motivation mechanism. That means a combination of reward and penalty produce a better result than that with only reward or penalty, which is in accordance with the result of $\mathrm{Wu}$ and Shi [17].

\subsection{Relationship between the revenue sharing coefficient and the monitoring signal}

Substituting related parameters with eq. (14), we have: $\beta=0.9-0.2 \gamma_{1}-0.1 \gamma_{2}$.

Simulating data by Origin 9.0, we arrived at the result shown in Fig. 3, where the $\mathrm{X}$ axis is the reward coefficient based on a monitoring signal, the $\mathrm{Y}$ axis is the penalty coefficient based on a monitoring signal and the $\mathrm{Z}$ axis is the revenue sharing coefficient. As seen in Fig. 3, the revenue sharing coefficient is the decreasing function of the reward coefficient and the penalty coefficient based on a monitoring signal; i.e., the larger reward coefficient and penalty coefficient, the lower the revenue sharing coefficient. This means, for the professional sub-contractor, the reward or penalty or both by the general contractor can deliver the same effect with a monitoring signal.

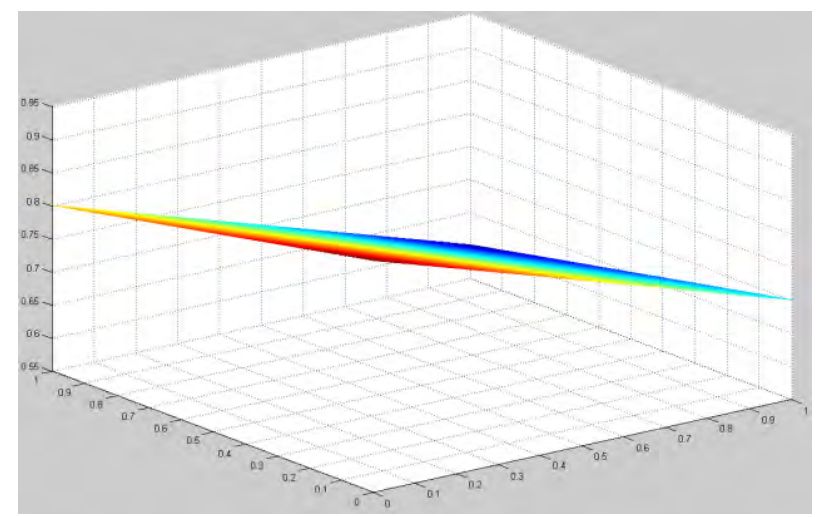

Figure 3: Relationship between the revenue sharing coefficient and the monitoring signal. 


\subsection{Relationship between the monitoring signal and the revenue of the general contractor and the professional sub-contractor}

Substituting related parameters with eqs. (9) and (10), we have:

$$
\left\{\begin{array}{l}
E(V)=0.1-3.4 \gamma_{1}+0.3 \gamma_{2}-0.2 \gamma_{1}^{2}+0.2 \gamma_{2}^{2}-0.2 \gamma_{1} \gamma_{2} \\
E(\mathrm{U})=6.5+0.8 \gamma_{1}-1.6 \gamma_{2}+0.4 \gamma_{1}^{2}-0.1 \gamma_{2}^{2}+0.6 \gamma_{1} \gamma_{2}
\end{array}\right.
$$

Simulating data by Origin 9.0, we arrive at Fig. 4, where the $\mathrm{X}$ axis is the reward coefficient based on a monitoring signal, the $\mathrm{Y}$ axis is the penalty coefficient based on a monitoring signal and the $\mathrm{Z}$ axis is the revenue of the general contractor or the professional sub-contractor.

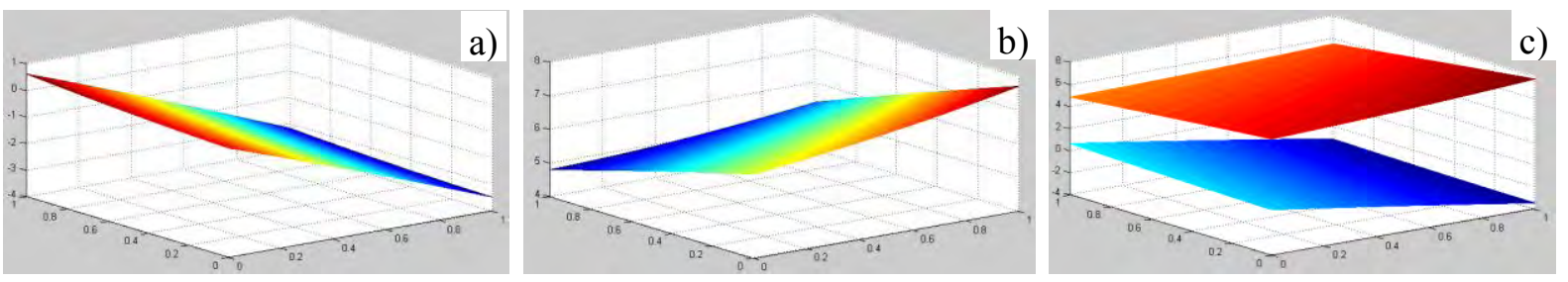

Figure 4: Relationship between the monitoring signal and the revenue of the general contractor and the professional sub-contractor; a) revenue of the professional sub-contractor, b) revenue of the general contractor, c) comparison the revenue of the general contractor and the professional sub-contractor.

As Fig. $4 \mathrm{a}$ and Fig. $4 \mathrm{~b}$ show, for the professional sub-contractor, its revenue increases as the reward coefficient based on a monitoring signal increases and the penalty coefficient decreases. On the contrary, for the general contractor, its revenue increases as the reward coefficient based on a monitoring signal decreases and the penalty coefficient decreases. As seen in Fig. $4 \mathrm{c}$, when the reward coefficient and penalty coefficient based on a monitoring signal fall between 0 and 1 , the revenue of the general contractor is always larger than that of the professional sub-contractor. In practice, the professional sub-contractor prefers more reward from the general contractor but the latter prefers to give more penalty. Therefore, it is crucial that the general contractor balance reward and penalty when designing a motivation mechanism to achieve a better effect.

\subsection{Model example}

With the model assumptions and given parameter values above, we took a sample analysis of the inter-organizational cooperative innovation of project-based supply chains model with a monitoring signal and considered six scenarios: (1) the general contractor gives the professional sub-contractor a reward only based on a monitoring signal; (2) the general contractor gives the professional sub-contractor a penalty only based on a monitoring signal; (3) the general contractor gives the professional sub-contractor both a reward and a penalty at the same level based on a monitoring signal; (4) the general contractor gives the professional sub-contractor more reward than penalty based on a monitoring signal; (5) the general contractor gives the professional sub-contractor less reward than penalty based on a monitoring signal; (6) the general contractor gives the professional sub-contractor both a reward and a penalty that are well balanced based on a monitoring signal. By giving different values to $\gamma_{1}$ and $\gamma_{2}$, we calculated the professional sub-contractor's knowledge sharing level, general knowledge sharing level, revenue sharing coefficient offered by the general contractor, revenue of the general contractor and revenue of the professional sub-contractor. The results are shown below in Table I. 
Table I: Model results under different monitoring signal.

\begin{tabular}{|c|c|c|c|c|c|c|c|}
\hline & $\gamma_{1}$ & $\gamma_{2}$ & $e_{1}$ & $e_{2}$ & $\beta$ & $E(V)$ & $E(U)$ \\
\hline \multirow{4}{*}{ Reward only } & 0.2 & 0 & 3.64 & 0.08 & 0.86 & -0.628 & 6.676 \\
\hline & 0.4 & 0 & 3.68 & -0.04 & 0.82 & -1.372 & 6.884 \\
\hline & 0.6 & 0 & 3.72 & -0.16 & 0.78 & -2.132 & 7.124 \\
\hline & 0.8 & 0 & 3.76 & -0.28 & 0.74 & -2.908 & 7.396 \\
\hline \multirow{4}{*}{$\begin{array}{l}\text { Punishment } \\
\text { only }\end{array}$} & 0 & 0.2 & 3.52 & 0.24 & 0.88 & 0.168 & 6.176 \\
\hline & 0 & 0.4 & 3.44 & 0.28 & 0.86 & 0.252 & 5.844 \\
\hline & 0 & 0.6 & 3.36 & 0.32 & 0.84 & 0.352 & 5.504 \\
\hline & 0 & 0.8 & 3.28 & 0.36 & 0.82 & 0.468 & 5.156 \\
\hline \multirow{4}{*}{$\begin{array}{l}\text { Synchronous } \\
\text { reward and } \\
\text { punishment }\end{array}$} & 0.2 & 0.2 & 3.56 & 0.12 & 0.84 & -0.568 & 6.376 \\
\hline & 0.4 & 0.4 & 3.52 & 0.04 & 0.78 & -1.252 & 6.324 \\
\hline & 0.6 & 0.6 & 3.48 & -0.04 & 0.72 & -1.952 & 6.344 \\
\hline & 0.8 & 0.8 & 3.44 & -0.12 & 0.66 & -2.668 & 6.436 \\
\hline \multirow{4}{*}{$\begin{array}{l}\text { Punishment } \\
\text { in dominant }\end{array}$} & 0.2 & 0.8 & 3.32 & 0.24 & 0.78 & -0.292 & 5.428 \\
\hline & 0.4 & 0.8 & 3.36 & 0.12 & 0.74 & -1.068 & 5.732 \\
\hline & 0.6 & 0.8 & 3.4 & 0 & 0.7 & -1.86 & 6.068 \\
\hline & 0.8 & 0.8 & 3.44 & -0.12 & 0.66 & -2.668 & 6.436 \\
\hline \multirow{4}{*}{$\begin{array}{l}\text { Reward in } \\
\text { dominant }\end{array}$} & 0.8 & 0.2 & 3.68 & -0.24 & 0.72 & -2.872 & 7.168 \\
\hline & 0.8 & 0.4 & 3.6 & -0.2 & 0.7 & -2.82 & 6.932 \\
\hline & 0.8 & 0.6 & 3.52 & -0.16 & 0.68 & -2.752 & 6.688 \\
\hline & 0.8 & 0.8 & 3.44 & -0.12 & 0.66 & -2.668 & 6.436 \\
\hline \multirow{4}{*}{$\begin{array}{l}\text { Reward and } \\
\text { punishment } \\
\text { in balance }\end{array}$} & 0.9 & 0.6 & 3.54 & -0.22 & 0.66 & -3.158 & 6.872 \\
\hline & 0.5 & 0.8 & 3.38 & 0.06 & 0.72 & -1.462 & 5.896 \\
\hline & 0.6 & 0.8 & 3.4 & 0 & 0.7 & -1.86 & 6.068 \\
\hline & 0.8 & 0.4 & 3.6 & -0.2 & 0.7 & -2.82 & 6.932 \\
\hline
\end{tabular}

Seen in Table I: (1) If the reward, offered by the general contractor, is attractive enough, the professional sub-contractor is sure to increase its knowledge sharing effort level and lower its knowledge concealing effort level. In this process, the general contractor will decrease the revenue sharing coefficient step by step so as to keep the professional sub-contractor's revenue steady. Because the reward provided by the general contractor based on a monitoring signal cannot cover the professional sub-contractor's cost of raising knowledge sharing effort level, its revenue will decrease on the whole. (2) In contrast, as to the scenario, where the general contractor gives penalty only, the professional sub-contractor will lower its knowledge sharing level as the penalty strengthens and increase its knowledge concealing level. Though the general contractor decreases the revenue sharing coefficient, the professional sub-contractor is able to increase its revenue by opportunism while the general contractor's total revenue decreases. (3) If the general contractor gives reward and penalty synchronously, the professional sub-contractor will lower its knowledge sharing and concealing level gradually. At the same time, the general contractor, to maintain its revenue, decreases the revenue sharing coefficient, leading to the professional sub-contractor's revenue to decline. (4) The effect with the penalty as dominant is better than that with the reward as dominant. In fact, with punishment as dominant, the professional sub-contractor will raise its knowledge sharing level and lower its knowledge concealing level. (5) There exists a point of equilibrium, where the professional sub-contractor's knowledge sharing level and knowledge concealing level are well balanced; i.e., the knowledge sharing level increases and the knowledge concealing level decreases. 


\section{CONCLUSIONS}

As to the possible moral risk involved with inter-organizational cooperative innovation of project-based supply chains, this paper studied the problem of knowledge sharing between the general contractor and the professional sub-contractor and built a motivational model based on a monitoring signal. Based on the model, the author performed data simulation and sample analysis, and made comparisons with the traditional model, and came to these results: (1) the general contractor is able to collect more information on the professional sub-contractor's knowledge sharing and concealing level, thus by adjusting the reward and penalty levels, it can not only lower the professional sub-contractor's knowledge concealing level, but also raise the knowledge sharing level, all of which will reduce the professional sub-contractor's opportunism and the ignorance the general contractor may incur in the design motivation mechanism; (2) the general contractor, when designing a motivation mechanism, should consider the professional sub-contractor's qualification, cost risk and risk attitude, etc., which helps it to combine the monitoring and the motivation mechanism so as to lower the revenue sharing coefficient, encourage the professional sub-contractor to make its behaviour beneficial to the general contractor, lessen the tendency of the professional sub-contractors to take risks of unscrupulous behaviour, and add to the profit of the whole supply chain.

Based on the above conclusions, we now have a deeper understanding of the following points. First of all, the general contractor, as the core enterprise, should try to create a cooperative and innovative environment for node enterprises and develop a motivational mechanism based on knowledge sharing and innovation. Second, the general contractor should build a trust mechanism among node enterprises so as to promote their knowledge communication and cooperation, which helps lower the knowledge sharing cost and raise the knowledge concealing cost. Lastly, the general contractor can promote cooperative innovation among node enterprises by establishing a knowledge communication platform and improving the knowledge sharing network. However, the model built in this paper is based on a series of reasonable assumptions such as the one-to-one relationship between the general contractor and the professional sub-contractor. Since the cooperative innovation among project-based organizations is much more complex in the real project-based supply chain and the general contractor's reward and penalty strategy becomes more complicated, the primary purpose of this paper is to arrive at some suggestions for raising the cooperation efficiency among project-based organizations through a model analysis, provide some new ideas for inter-organizational cooperative innovation of project-based supply chains and put forward some targeted and practical solutions for raising project value-adding.

\section{ACKNOWLEDGEMENT}

This work was supported by National Natural Science Funds of China (Grant No. 71301065, 71561009), University Social Sciences and Humanities Funds of Jiangxi Province (Grant No. JC1309, Grant No. JC1403), Scientific and technological research Funds of Department of Education of Jiangxi Province (Grant No. GJJ14341).

\section{REFERENCES}

[1] Ribeiro, F. L. (2009). Enhancing knowledge management in construction firms, Construction Innovation, Vol. 9, No. 3, 268-284, doi:10.1108/14714170910973493

[2] Chen, Y.; You, J.-X. (2006). Qualitative simulation of engineering project collaboration performance in supply chain, China Civil Engineering Journal, Vol. 39, No. 2, 113-116, doi:10.15951/j.tmgcxb.2006.02.021 
[3] Wei, G. X.; Yu, L. A.; Wang, S. Y. (2007). A study on incentive factors of team cooperation based on synergy effect, Systems Engineering - Theory \& Practice, No. 1, 1-9

[4] Liu, L.; Li, N. (2009). Study on improving profit allocation in virtual enterprises of construction project, China Civil Engineering Journal, Vol. 42, No. 1, 135-139, doi:10.15951/ j.tmgcxb.2009.01.021

[5] Xue, X.-L.; Wang, Y.-W.; Shen, Q.-P.; Yu, X.-G. (2007). Coordination mechanisms for construction supply chain management in the Internet environment, International Journal of Project Management, Vol. 25, No. 2, 150-157, doi:10.1016/j.ijproman.2006.09.006

[6] Parrod, N.; Thierry, C.; Fargier, H.; Cavaille, J. B. (2007). Cooperative subcontracting relationship within a project supply chain: a simulation approach, Simulation Modelling Practice and Theory, Vol. 15, No. 2, 137-152, doi:10.1016/j.simpat.2006.09.016

[7] Kumaraswamy, M. M.; Ng, S. T.; Ugwu, O. O.; Palaneeswaran, E.; Rahman, M. M. (2004). Empowering collaborative decisions in complex construction project scenarios, Engineering, Construction and Architectural Management, Vol. 11, No. 2, 133-142, doi:10.1108/09699980410527876

[8] He, Q.; Ghobadian, A.; Gallear, D. (2013). Knowledge acquisition in supply chain partnerships: the role of power, International Journal of Production Economics, Vol. 141, No. 2, 605-618, doi:10.1016/j.ijpe.2012.09.019

[9] Ramanathan, U. (2014). Performance of supply chain collaboration - a simulation study, Expert Systems with Applications, Vol. 41, No. 1, 210-220, doi:10.1016/j.eswa.2013.07.022

[10] Ramanathan, U.; Gunasekaran, A. (2014). Supply chain collaboration: impact of success in long-term partnerships, International Journal of Production Economics, Vol. 147, Part B, 252-259, doi:10.1016/j.ijpe.2012.06.002

[11] He, Q.-H.; Chen, Z.; Li, Y.-K. (2014). Game strategy study of design subcontracting rights and responsibilities based on knowledge innovation, Journal of Tongji University (Natural, Science), Vol. 42, No. 3, 488-492, doi:10.3969/j.issn.0253-374x.2014.03.025

[12] Zhou, W.-L. (2013). A study on knowledge innovation performance evaluation of service-oriented manufacturing enterprises in supply chain based on DEA, Science and Technology Management Research, Vol. 2013, No. 20, 147-151

[13] Wu, G.-D.; Shi, J.-G.; Tang, D.-H. (2011). Project-based supply chain cross-organizational bi-directional incentives based on fairness preference theory, Journal of Tongji University (Natural, Science), Vol. 39, No. 9, 1394-1400, doi:10.3969/j.issn.0253-374x.2011.09.026

[14] Ma, Y.-D.; Zhang, X.-M.; Chen, W. (2012). Incentive mechanism for knowledge sharing considering monitoring signal, Chinese Journal of Management, Vol. 9, No. 12, 1838-1855

[15] Wu, G. D. (2014). Project-based supply chain cooperative incentive based on reciprocity preference, International Journal of Simulation Modelling, Vol. 13, No. 1, 102-115, doi:10.2507/IJSIMM13(1)CO3

[16] Chiang, W.-Y. K. (2010). Product availability in competitive and cooperative dual-channel distribution with stock-out based substitution, European Journal of Operational Research, Vol. 200, No. 1, 111-126, doi:10.1016/j.ejor.2008.12.021

[17] Wu, G. D.; Shi, J. G. (2013). Project-based supply chain cross-organizational multi-periods dynamic incentives based on bonus-penalty structure, Operations Research and Management Science, Vol. 22, No. 3, 248-255 